\title{
Influence of Socio-cultural and Physical Factors on Use of Skilled Birth Attendants by Pregnant Women at Central Region
}

\author{
Christiana Asiedu \\ Department of Maternal and Child Health, College of Health and Allied Health Sciences, University of Cape Coast, Ghana
}

Received May 3, 2019; Revised May 28, 2019; Accepted June 4, 2019

Copyright@2019 by authors, all rights reserved. Authors agree that this article remains permanently open access under the terms of the Creative Commons Attribution License 4.0 International License

\begin{abstract}
The purpose of the study was to assess the effects of socio-cultural and physical factors on the use of SBAs in the Central Region of Ghana. Among socio-cultural and physical factors which may influence use of SBAs with current pregnancy were money for transport and health care (65\%), distance (58\%), knowledge about signs of labor (51\%), and need for closer attention from relatives (51\%). The differences from the two logistic regression model analysis that were done were statistically significant $\left(\chi^{2}=7.06, \mathrm{p}=0.0079\right)$. The odds of SBA utilization for mothers who needed closer attention from relatives were 1.6 times higher $(\mathrm{OR}=1.56,95 \%$ $\mathrm{CI}=1.05-2.34$, p-value $=0.027$ ) than mothers who did not need closer attention. It was recommended that health service providers should ensure client and family-centered care is provided to make the health facilities user-friendly.
\end{abstract}

Keywords Socio-culture Factors, Maternal Mortality, Physical Factors, Pregnant Women, Utilization of Skilled Delivery Services

\section{Introduction}

Skilled Birth Attendant (SBA) is an accredited health professional (midwife, doctor or nurse) who has been educated and trained to proficiency in the skills needed to manage normal (uncomplicated) pregnancy, childbirth and the immediate postnatal period, and in the identification, management and referral of complications in women and new-borns (1). SBA are trained to be present at childbirth, to recognize and respond appropriately to medical complications, and to implement interventions to prevent complications associated with delivery (1). Cultural factors and accessibility to health care are key determinants for pregnant women in Sub-Saharan Africa (SSA) to use maternal health services (1). Maternal health services are mostly used less by women who travel long distances (2). The dominant aspect of culture, which is expected by pregnant women at health facilities, is respectful communication during labour and birth (3, 4). Accessibility of health care is influenced by physical and social resources (5). Women who travel less than 60 minutes to access health facility are 1.5 times more likely to use skilled birth attendants (SBAs) $(\mathrm{OR}=1.5$; 95\% CI = 1.1- 2.0) than women who travel more than 60 minutes (6). Women who live more than 5 kilometers away from a health facility are four times less likely to deliver at a health facility compared with those living within a 5 kilometer range to a health facility $(7,8)$.

In a study done at Bangladesh, urban women from richest wealth group are about 19 times more likely to use SBA (OR= 18.86, CI: 9.79-36.31) than rural women from the same wealth grouping $(9,10)$. Pregnant women in rural areas are less likely to use SBA compared with those in urban areas $(\mathrm{OR}=0.73,95 \% \mathrm{CI}=0.51-0.95)(11,12)$. Other explanations could be attributed to poor road networks mostly in rainy seasons, which prevent vehicles from using such roads $(13,14)$. Unreliable transport is also a barrier to access skilled delivery in rural areas, the failure to plan for transport causes higher number of women to deliver in their homes even if they had planned to deliver in health facilities $(14,15)$. Expenses of transportation, poor or non-existent road links and time needed to access health care services influence the rate at which people use the health services they need (16-18). While other elements certainly affect the SBA utilization, the concepts of cultural and physical are central to understanding determinants of utilization of SBAs. About $90 \%$ of Ghanaian women in urban areas used SBAs during their most recent births compared with 59\% of women in the rural areas (19). The study therefore sought to investigate the effects of cultural and physical factors on the use of skilled birth attendants 
by women in reproductive age in the Central Region of Ghana.

\section{Materials and Methods}

\subsection{Research Design}

Cross-sectional survey was quantitatively explored with socio-cultural and physical factors influencing the utilization of SBAs in Central Region of Ghana. Cross-sectional studies can help make health-policy decisions. Cross-sectional surveys enabled the researcher to gather information on important health-related aspects of the study population. Cross-sectional studies are done on representative samples of the population if generalizations from the findings are to have any validity. The aim of cross-sectional survey is to describe the relationship between dependent and independent variables depending on their prevalence in a specified population at a particular time, without regard for what may have preceded or precipitated the health status found at the time of the study. Cross-sectional studies are done on representative samples of the population if generalizations from the findings are to have any validity.

\subsection{Study Area}

The study focuses on the public health facilities in the Central Region of Ghana. Central Region occupies an area of 9,826 square kilometers, which is about $6.6 \%$ of the total land area of Ghana. It is bounded on the south by the Gulf of Guinea and on the west by the Western Region. The region shares borders on the east with the Greater Accra Region, on the north with Ashanti Region and on the north-east with Eastern Region. The region has 20 administrative districts with the historical city of Cape Coast as the capital. About $63 \%$ of the region is rural. The population was estimated at 2,413,050 for the year 2013 with an annual growth rate of $3.1 \%$ and a population density of about 215 inhabitants per square utilization (19, 20). The predominant industry in the region is agriculture (52.3\%). Manufacturing forms $10.5 \%$ of industries in the region. Agriculture (including fishing) is therefore the main occupation and employs more than two thirds of the workforce in the region. Cocoa and oil palm production is concentrated at Assin North and South, Twifo-Hemang-Lower Denkyira and Upper Denkyira East and West districts. Other major agricultural enterprises include pineapple and grain production. Fishing is concentrated mainly in the Coastal areas.

\subsection{Population}

The target population included all antenatal care (ANC) clients between 15-49 years who have delivered within the past three years prior to the study in Central Region, regardless of their birth outcome and first-time pregnant women.

\subsection{Sample and Sampling Procedure}

There were 20 districts in the region and 10 were selected for the study. Sample size estimation was done to sample 1100 ANC clients out of 45,759 expected pregnancies in the selected hospitals. The formula by Krejcie and Morgan was used for estimating the sample size (21). Multi-stage cluster sampling was used to select the respondents for the study.

\subsection{Data Collection Instrument}

A modified version of the safe motherhood questionnaire developed by GSS (19) was used. The items on the questionnaire were money for transport and health care, cultural, religious beliefs and custom, decision making power, health facility in the community, distance, road networks, husband/partner/family members influence, knowledge about signs of labour, need for closer attention from relatives, comfortable when delivered at home and community and family support. The response options for all the items in this were "Strongly Agree", "Agree", "Disagreed", and "Strongly Disagreed", which were re-categorized as "Agree" and "Disagree". The variables were coded 1 if the response was "Disagree" and 2 if the response was "Agree".

\subsection{Data Collection Procedure}

Ethical clearance was sought from the University of Cape Coast Ethical Review Board and Ghana Health Service, Ethics Review Committee. Approval was sought from the Central Regional Health Directorate and permission sought from the district health directors, hospital management and ANC in charge. Informed consent forms were used to solicit the consent of the study participants. Anonymity was assured of confidentiality.

\subsection{Data Analysis}

Data collected from respondents were processed using Predictive Analytic Software (PASW). Logistic regression and descriptive analysis were done.

\subsection{Ethical Considerations}

Ethical clearance was sought from Ghana health service ethical review committee and University of Cape Coast ethical board. Consent for participating in the study was sought from the respondents by explaining the purpose of the study to them and assuring them of confidentiality. A consent form was made available to the respondents to sign 
before the administration of the questionnaire. Those who could not read and write thumb printed the consent forms when they agreed to participate in the study. Participation in the study was voluntary and anonymity was ensured. The duration and period for the data collection was explained to the participants.

\section{Results}

Socio-cultural and physical factors which may influence decisions regarding use of SBAs with current pregnancy were money for transport and health care $65 \%(n=716)$, distance $58 \%(n=635)$, knowledge about signs of labour $51 \%(\mathrm{n}=565)$, and need for closer attention from relatives $51 \%(\mathrm{n}=562)$, as shown in Table 1 .

From the logistic regression model which has only socio-cultural and physical factors as predictors to a model that controls for socio-demographic factors, the difference in AUROC between the two nested models was statistically significant $\left(\chi^{2}=7.06, \mathrm{p}=0.0079\right)$. The best performing model that explained the variations in SBA was the model with socio-cultural and physical factors controlling for the possible confounding effect of socio-demographic characteristics of the study participants (AUROC $=71.23 \%$, $\mathrm{AIC}=578.46$ ) (Table 2). Graph depicting the performance of the models is shown in Figure 1.

In the model that socio-demographic factors were not controlled, road network and need for closer attention from relatives were found to be associated with SBA use. The odds of SBAs utilization for mothers who needed closer attention from relatives were 1.6 times higher $(\mathrm{OR}=1.56$, $95 \% \mathrm{CI}=1.05-2.34, p$-value $=0.027$ ) than mothers who did not need closer attention. None of the socio-cultural and physical factors were found to be related to SBA in the multivariable logistic regression model controlling for socio-demographic factors $(p>0.05)$ with the exception of need for closer attention from relatives and feeling comfortable when delivered at home which even assumed borderline significant effect on SBA $(p<0.070)$ (Table 2).

Table 1. Socio-cultural and physical factors influencing intended delivery place with current pregnancy

\begin{tabular}{|c|c|c|c|}
\hline \multirow[t]{2}{*}{ Variable } & \multicolumn{2}{|c|}{ Use of SDS with current pregnancy } & \multirow{2}{*}{$\begin{array}{l}\text { Total } \\
\%(\mathrm{~N}) \\
\end{array}$} \\
\hline & No $\%(\mathrm{~N})$ & Yes \% (N) & \\
\hline \multicolumn{4}{|c|}{ Money for transport and health care } \\
\hline Disagree & 40.6(89) & $33.5(295)$ & $34.9(384)$ \\
\hline Agree & $59.4(130)$ & $66.5(586)$ & $65.1(716)$ \\
\hline \multicolumn{4}{|l|}{ Distance } \\
\hline Disagree & $48.9(107)$ & $40.6(358)$ & 42.3(465) \\
\hline Agree & $51.1(112)$ & $59.4(523)$ & $57.7(635)$ \\
\hline \multicolumn{4}{|c|}{ Husband/partner/family members' influence } \\
\hline Disagree & $59.8(131)$ & $50.3(443)$ & $52.2(574)$ \\
\hline Agree & $40.2(88)$ & 49.7(438) & $47.8(526)$ \\
\hline \multicolumn{4}{|c|}{ Knowledge about signs of labour } \\
\hline Disagree & $53.9(118)$ & 47.3(417) & 48.6(535) \\
\hline Agree & $46.1(101)$ & $52.7(464)$ & $51.4(565)$ \\
\hline \multicolumn{4}{|c|}{ Need for closer attention from relatives } \\
\hline Disagree & $57.5(126)$ & $46.8(412)$ & $48.9(538)$ \\
\hline Agree & 42.5(93) & $53.2(469)$ & $51.1(562)$ \\
\hline \multicolumn{4}{|c|}{ Comfortable when delivered at home } \\
\hline Disagree & $64.4(141)$ & $65.0(573)$ & $64.9(714)$ \\
\hline Agree & $35.6(78)$ & $35.0(308)$ & 35.1(386) \\
\hline \multicolumn{4}{|c|}{ Community and family support } \\
\hline Disagree & $51.6(113)$ & $49.9(440)$ & $50.3(553)$ \\
\hline Agree & 48.4(106) & $50.1(441)$ & 49.7(547) \\
\hline
\end{tabular}


Table 2. The effects of socio-cultural and physical factors on skilled birth attendant

\begin{tabular}{|c|c|c|c|c|c|c|c|c|}
\hline \multirow[b]{3}{*}{$\begin{array}{l}\text { Socio-cultural and } \\
\text { physical factors }\end{array}$} & \multicolumn{4}{|c|}{ Skilled Birth Delivery } & \multicolumn{4}{|c|}{ Skilled Birth Delivery } \\
\hline & \multicolumn{4}{|c|}{$\begin{array}{l}\text { Unadjusted effect of socio-cultural and physical } \\
\text { factors on SBA: model } 1\end{array}$} & \multicolumn{4}{|c|}{$\begin{array}{l}\text { Effect of socio-cultural and physical factors on SBA } \\
\text { controlling for Sociodemographic factors: model } 2\end{array}$} \\
\hline & OR & $95 \% \mathrm{CI}$ & $\mathrm{p}$-value & Wald & aOR & $95 \% \mathrm{CI}$ & p-value & Wald \\
\hline \multicolumn{9}{|c|}{ Money for transport and health care } \\
\hline Disagree & ref & & & & ref & & & \\
\hline Agree & 1.10 & $0.76-1.60$ & 0.778 & 0.28 & 1.03 & $0.70-1.53$ & 0.873 & 0.16 \\
\hline \multicolumn{9}{|l|}{ Distance } \\
\hline Disagree & ref & & & & ref & & & \\
\hline Agree & 1.19 & $0.83-1.71$ & 0.342 & 0.95 & 1.11 & $0.76-1.62$ & 0.585 & 0.55 \\
\hline \multicolumn{9}{|c|}{ Husband/partner/family members' influence } \\
\hline Disagree & ref & & & & ref & & & \\
\hline Agree & 1.32 & $0.91-1.94$ & 0.143 & 1.46 & 1.23 & $0.82-1.84$ & 0.798 & 0.26 \\
\hline \multicolumn{9}{|c|}{ Knowledge about signs of labour } \\
\hline Disagree & ref & & & & ref & & & \\
\hline Agree & 1.07 & $0.74-1.56$ & 0.711 & 0.37 & 1.05 & $0.71-1.55$ & 0.798 & 0.26 \\
\hline \multicolumn{9}{|c|}{ Need for closer attention from relatives } \\
\hline Disagree & ref & & & & ref & & & \\
\hline Agree & 1.56 & $1.05-2.34$ & $0.027 *$ & 2.15 & 1.51 & $0.99-2.28$ & 0.054 & 1.93 \\
\hline \multicolumn{9}{|c|}{ Comfortable when delivered at home } \\
\hline Disagree & ref & & & & ref & & & \\
\hline Agree & 0.76 & $0.53-1.09$ & 0.133 & -1.50 & 0.71 & $0.49-1.03$ & 0.069 & -1.82 \\
\hline \multicolumn{9}{|c|}{ Community and family support } \\
\hline Disagree & ref & & & & ref & & & \\
\hline Agree & 0.72 & $0.49-1.06$ & 0.094 & -1.68 & 0.81 & $0.54-1.22$ & 0.324 & -0.99 \\
\hline AUROC $(95 \%$ CI $)$ & 63.14 & $9.70-69.48)$ & & & 70.12 & $87-78.60)$ & & \\
\hline AIC & 1078 & & & & 588.4 & & & \\
\hline HL GOF & $x^{2}=\varepsilon$ & $p=0.4591$ & & & $x^{2}=1$ & $\mathrm{p}=0.044$ & & \\
\hline
\end{tabular}

Ref: reference category, ${ }^{*} \mathrm{p}<0.05,{ }^{* *} \mathrm{p}<0.01,{ }^{* * *} \mathrm{p}<0.001$ aOR: Odds ratio adjusted for sociodemographic factors, OR: Odds ratio based on only socio-cultural and physical factors, AIC: Akaike Information Criterion, AUROC: Area Under Receiver Operating Curve, HL GOF: Hosmer Lameshow Goodness of Fit, SBA: Skilled Birth Attendant 


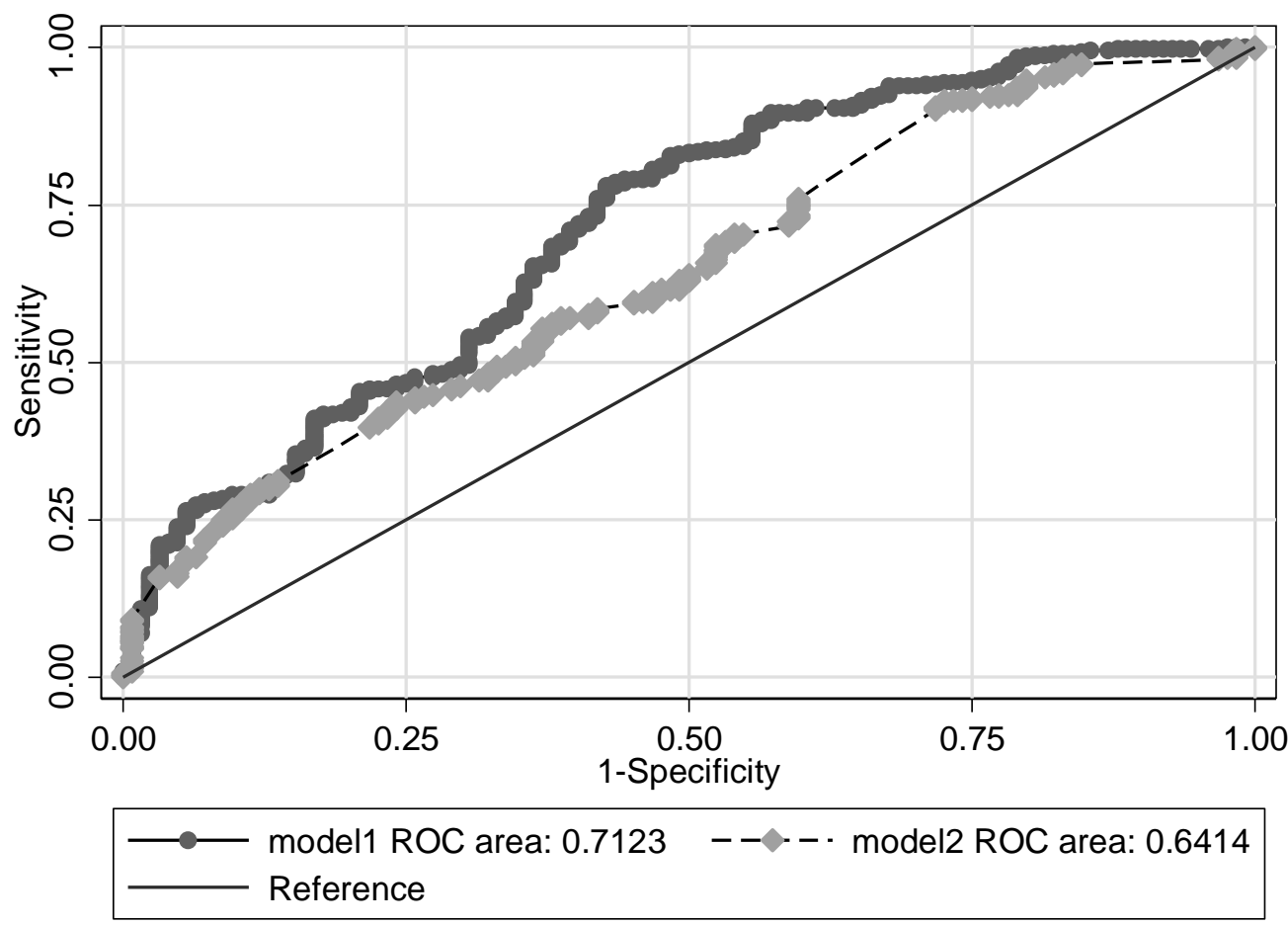

Figure 1. Performance of the models

\section{Discussions}

This study did not find significant effect of most of the socio-cultural and physical factors on use of SBA which is inconsistent with the findings of several authors (22-25). The fact that they feel comfortable when delivered at home, community and family support had moderate influence on SBA use. This finding is consistent with similar community based multi-stage sampling cross-sectional study conducted among mothers who gave birth in the last 12 months in Sekela District, Amhara Region and Ethiopia (25) using multivariable logistic regression analysis. The findings from a study conducted in Ethiopia replicates the findings of this study where mothers feel comfortable and have their privacy when delivering at home compared with health facility $(26,27)$.

Households with woefully inadequate budget will have great difficulties in paying for costs and therefore be less likely to use SBA. These could have influence on SBA as have been found by other studies $(28,29)$. The effect of availability of health facility in the community, distance to facility and road network on facility delivery are inter-related. These could prevent women from seeking assisted delivery in health facility (30). However, this study did not find significant effect of distance to facility and road network. This could partly be due to the fact that Central Region has seen massive improvement in the area of road network and tremendous availability of health facilities. Both the univariate and multivariable logistic regression analysis did not find any effect of knowledge about signs of labor, which was consistent with studies in Southern Laos (31) but contradicted the findings of a study conducted in Zambia (32) that showed that women in Zambia who know danger signs in pregnancy are more likely to deliver in a health facility as compared with those without such knowledge.

In a developing country such as Ghana, some women cannot decide on their own to seek care, but have to seek permission from a husband or any other person in authority mostly when the woman is unemployed and financially handicapped $(33,27)$. However, this study did not find women autonomy to be statistically significant. This may be partly due to the fact that women in some communities in the Central Region are rather not key decision makers in the household and moreover gainfully employed compared with their partners which could reduce the chances of delivering outside health facilities. It is paramount to note that autonomy effect is likely to be modified by age, marital status, wealth and parity (34).

\section{Conclusions}

The government through the $\mathrm{MOH}$ and GHS must provide in-service training for SBAs to provide services that will ensure that family members will have close contact with their relatives when they are on admission. SBAs must ensure good relationship with their clients to enable them to identify things that will make them feel comfortable to use SDS. 


\section{Acknowledgements}

I am highly indebted to various writers from whom references were made. I would like to thank all other individuals who provided the needed support for me to complete this study.

\section{REFERENCES}

[1] M. Tsawe, A. S. Susuman. Determinants of access to and use of maternal health care services in the Eastern Cape, South Africa: A quantitative and qualitative investigation. BMC Research Notes, 2014; 7(1), $723 . \quad$ doi: 10.1186/1756-0500-7-723.

[2] J. Mattson. Transportation, distance, and health care utilization for older adults in rural and small urban areas. Transportation Research Record. 2011; 2265, 192-199.

[3] M. J. Renfrew, A. McFadden, M. H. Bastos, J. Campbell, A. A. Channon, N. F. Cheung, F. McCormick. Midwifery and quality care: Findings from a new evidence-informed framework for maternal and newborn care. The Lancet. 2014; 384(9948), 1129-1145.

[4] J. K. Ganle, B. Obeng, A. Y. Segbefia, V. Mwinyuri, J.Y. Yeboah, L. Baatiema. How intra-familial decision-making affects women's access to, and use of maternal healthcare services in Ghana: A qualitative study. BMC Pregnancy and Childbirth. 2015; 15(1), 173. doi: 10.1186/s12884-015-0590-4.

[5] S. LaVela, B. Smith, F. Weaver, S. Miskevics. Geographical Proximity and Health Care Utilization in Veterans with SCI \& D in the USA. J. Soc. Sci. Med. 2004; 59(11), 2387-2399.

[6] M. Mayhew,P.M. Hansen, D. H. Peters, A. Edward, L. P. Singh, V. Dwivedi, G. Burnham. Determinants of skilled birth attendant utilization in Afghanistan: A cross-sectional study. American Journal of Public Health. 2008; 98(10), 1849-1856.

[7] A. Gitimu, C. Herr, H. Oruko, E. Karijo, R. Gichuki, P. Ofware ... J. Nyagero. Determinants of use of skilled birth attendant at delivery in Makueni, Kenya: A cross sectional study. BMC Pregnancy and Childbirth. 2015; 15(1), 9. doi: 10.1186/s12884-015-0442-2.

[8] G. Samson. Utilization and factors affecting delivery in health facility among recent delivered women in Nkasi District. Unpublished masters dissertation, Muhimbili University of Health and Allied Sciences (MUHAS). 2012.

[9] S. Bashar, K. Dahlblom, H. Stenlund. Determinants of the use of skilled birth attendants at delivery by pregnant women in Bangladesh. Unpublished masters dissertation, Department of Public Health and Clinical Medicine, Epidemiology and Global Health, Umeå International School of Public Health, Umeå University, Sweden. 2012.

[10] C. M. Kanini, H. Kimani, P. Mwaniki. Utilisation of Skilled Birth Attendants among women of reproductive age in Central District, Kitui County, Kenya. African Journal of Midwifery \& Women's Health. 2013; 7(2), 80-86.

[11] S. Pongpanich, A. Ghaffar, N. Ghaffar, T. Mehmood. Skilled birth attendance in Balochistan, Pakistan. Asian Biomedicine. 2016; 10(1), 25-34.

[12] V. N. Yakong. Rural Ghanaian women's experiences of seeking reproductive health care. Unpublished Master of Science thesis. Columbia: The College of Graduate Studies, The University of British. 2008.

[13] Y. R. Baral, K. Lyons, J.V.T.E. Skinner. Determinants of skilled birth attendants for delivery in Nepal. Kathmandu Univ Med. 2010; 8(31): 325-32.

[14] M. Magoma, J. Requejo, O. M. Campbell, S. Cousens, V. Filippa. High ANC coverage and low skilled attendance in a rural Tanzanian district: A case for implementing a birth plan intervention. BMC Pregnancy and Childbirth. 2010; 10(13). Available at http://www.biomed central.com/1471-2393/10/13

[15] M. Mrisho, J. A. Schellenberg, A. K. Mushi, B. Obrist, H. Mshinda, M. Tanner, D. Schellenberg. Factors affecting home delivery in rural Tanzania. Tropical Medicine \& International Health. 2007; 12(7), 862-872.

[16] R. King, R. Jackson, E. Dietsch, A. Hailemariam. Barriers and facilitators to accessing skilled birth attendants in Afar region, Ethiopia. Midwifery. 2015; 31(5), 540-546.

[17] J. Borghi, T. Ensor, B. D. Neupane, S. Tiwari. Financial implications of skilled birth attendance at delivery in Nepal. Trop M Int Health. 2006; 2(II), 228-237.

[18] A. S. Furber. Referral to hospital in Nepal: 4 years' experience in one rural district. Trop Doct. 2002; 32, 75-78.

[19] Ghana Statistical Service (GSS), Ghana Health Service (GHS), \& ICF International. Ghana Demographic and Health Survey 2014: Key indicators report. Maryland: Authors.2015.

[20] J. H. Abramson, Z. H. Abramson. Survey Methods in Community Medicine, 5th edition. Edinburgh \& London: Livingstone. 2000.

[21] R. V. Krejcie, D. W. Morgan. Determining sample size for research activities. Educational and Psychological Measurement. 1970; 30(3), 607-610.

[22] H. Abraha, B. F. Hurissa. Prevalence of Institutional Delivery Service Utilization and Associated Factors among Women of Child Bearing Age in Tahtay Adiabo District, North West Ethiopia, 2014. Journal of Womens Health, Issues and Care. 2016.

[23] T. Azilke. Exploring Selected Maternity Service Utilization among Homeless Mothers in Addis Ketema Sub-City, Addis Ababa, Ethiopia: Descriptive Phenomenological Qualitative Study. AAU, 2016.

[24] T. Gultie, B. Wasihun, M. Kondale, B. Balcha. Home Delivery and Associated Factors among Reproductive Age Women in Shashemene Town, Ethiopia. J Women's Health Care. 2016; 5(300), 2167-0420.1000300.

[25] A. Seme, A. Seifu. Institutional Delivery Services Utilization by Women of Childbearing Age in South West Showa Zone, Oromia Region. Ethiopian Medical Journal. 2016; 55(1).

[26] Z. Tenaw, M. Mekonnen, M. Mengistu, T. Getahun. Magnitude and Factors Associated with Institutional 
Delivery Service among Women who have Antenatal Care Follow-Up at Hawassa University Referral Hospital, Ethiopia, 2016. Diversity \& Equality in Health and Care. 2017.

[27] S. Thaddeus, D. Maine. Too far to walk: maternal mortality in context. Social science \& medicine. 1994; 38(8), 1091-1110.

[28] A. Amano, A. Gebeyehu, Z. Birhanu. Institutional delivery service utilization in Munisa Woreda, South East Ethiopia: a community based cross-sectional study. BMC pregnancy and childbirth. 2012; 12(1), 105.

[29] K. Navaneetham, A. Dharmalingam. Utilization of maternal health care services in Southern India. Social science \& medicine. 2002; 55(10), 1849-1869.

[30] S. Yanagisawa, S. Oum, S. Wakai. Determinants of skilled birth attendance in rural Cambodia. Tropical Medicine \& International Health. 2006; 11(2), 238-251.

[31] C. Phoxay, J. Okumura, Y. Nakamura, S. Wakai. Influence of women's knowledge on maternal health care utilization in southern Laos. Asia pacific journal of public health.2001; 13(1), 13-19.

[32] J. Stekelenburg, S. Kyanamina, M. Mukelabai, I. Wolffers, J. V. Roosmalen. Waiting too long: low use of maternal health services in Kalabo, Zambia. Tropical Medicine \& International Health. 2004; 9(3), 390-398.

[33] M. Furuta, S. Salway. Women's position within the household as a determinant of maternal health care use in Nepal. International family planning perspectives. 2006; $17-27$.

[34] S. Gabrysch, O. M. Campbell. Still too far to walk: literature review of the determinants of delivery service use. BMC pregnancy and childbirth. 2009; 9(1), 34. 